\title{
UM RETRATO DA EVOLUÇÃO URBANA DE VIÇOSA-MG: IMPACTOS DA FEDERALIZAÇÃO DA UFV SOBRE A CIDADE (1969-2014)
}

\section{A PORTRAIT OF URBAN DEVELOPMENT OF VIÇOSA-MG: UFV IMPACTS OF THE FEDERALIZATION OVER CITY (1969-2014)}

\author{
Ana Cristina de Souza Maria ${ }^{1}$ \\ Teresa Cristina de Almeida Faria ${ }^{2}$ \\ Italo Itamar Caixeiro Stephan ${ }^{3}$
}

\section{RESUMO}

Viçosa, Minas Gerais, possui hoje seu nome evidenciado pela Universidade Federal de Viçosa (UFV), que nela se inseriu na segunda década do século XX. Essa ação condicionou o município a se tornar um polo educacional de destaque em Minas Gerais, no Brasil e no mundo. O trabalho consistiu na apresentação de um estudo de caso que teve como objetivo apresentar reflexões acerca da evolução urbana da cidade sob a luz da federalização da UFV. Esse processo, ocorrido no final dos anos 1960, implicou mudanças significativas no espaço urbano da cidade, que se expandiu tanto verticalmente, com a construção de edifícios nas áreas centrais para atender à demanda proveniente da UFV; bem como se espraiou horizontalmente, com a proliferação de parcelamentos irregulares de solo nas franjas urbanas e em áreas rurais com a construção de loteamentos e condomínios fechados. Torna-se necessário pensar no impacto desse espraiamento, sobretudo em direção às áreas periurbanas e rurais. A cidade se expande horizontalmente e os vazios urbanos são deixados para trás.

Palavras-chave: Expansão Urbana. Parcelamento do solo. Viçosa-MG. UFV. Urbanização Extensiva.

\begin{abstract}
Viçosa, Minas Gerais, now has his name evidenced by the Federal University of Viçosa, that it was inserted in the second decade of the twenty century. This action has conditioned the municipality to become a prominent educational hub in Minas Gerais, in Brazil and world. The work consisted in presenting a case study that aimed to present reflections on the urban evolution of the city in the light of federalization of UFV. This process, after the end of the 1960 s, resulted in significant changes in the urban space of the city, which expanded both vertically, with the construction of buildings in the central areas to meet the demand from the UFV; and spilled over horizontally, with the proliferation of irregular land subdivisions in urban fringes and rural areas with the construction of subdivisions and condominiums. It is necessary to think about the impact of this spreading, especially toward the peri-urban and rural areas. The city expands horizontally and urban voids are left behind.
\end{abstract}

Keywords: Urban sprawl. Division of Land. Viçosa-MG. UFV. Extensive urbanization.

\footnotetext{
${ }^{1}$ Universidade Federal de Viçosa, mestranda em Planejamento do Espaço Urbano e Regional pelo Programa de Pós-Graduação em Arquitetura e Urbanismo (PPG-AU) da Universidade Federal de Viçosa (2014) - Avenida Peter Henry Rolfs, s/n - Campus Universitário, Viçosa, MG - CEP 36570-900. E-mail: ana.c.s.maria@ gmail.com

${ }^{2}$ Universidade Federal de Viçosa. Graduação em Arquitetura e Urbanismo pela Universidade Santa Úrsula (1983); mestrado (1997) e doutorado (2004) em Planejamento Urbano e Regional pelo Instituto de Pesquisa e Planejamento Urbano e Regional (IPPUR) da Universidade Federal do Rio de Janeiro (UERJ). Atualmente, professora adjunta do Departamento de Arquitetura e Urbanismo da Universidade Federal de Viçosa, MG - Avenida Peter Henry Rolfs, s/n - Campus Universitário, Viçosa, MG - CEP 36570-900. Email: teresa.faria@ufv.br

${ }^{3}$ Universidade Federal de Viçosa. Arquiteto e urbanista pela Universidade Federal do Rio de Janeiro (UFRJ, 1982), mestre em Urban and Rural Planning - Technical University of Nova Scotia (Halifax, Canadá, 1996) e doutor em Arquitetura e Urbanismo pela Faculdade de Arquitetura e Urbanismo da Universidade de São Paulo (USP, 2006) - Avenida Peter Henry Rolfs, s/n - Campus Universitário, Viçosa, MG - CEP 36570-900. E-mail: stephan@ufv.br
} 


\section{Introdução}

O tema deste texto é a evolução urbana de Viçosa, Minas Gerais, experimentada após os anos conseguintes à federalização da Universidade Federal de Viçosa (UFV). Viçosa é um município de médio porte localizado na Zona da Mata mineira, e possui aproximadamente 77.502 habitantes (IBGE, 2014) e uma população "flutuante" estimada em quase 20 mil pessoas que migram para a cidade devido à existência de instituições de ensino superior. A UFV se originou da construção da Escola Superior de Agricultura e Veterinária, em 1922, idealizada pelo viçosense Arthur Bernardes. Buscando o desenvolvimento da escola, em 1948, o governo do Estado a transformou em Universidade Rural do Estado de Minas Gerais (UREMG).

A federalização da antiga UREMG sucedeu-se em 1969, sob a forma de fundação. A partir dessa época, a então Universidade Federal de Viçosa, agente determinante da produção do espaço urbano viçosense, com seu crescente desenvolvimento, começou a demandar uma infraestrutura de cidade. Viçosa se transformou, então, para atender a população migrante composta de estudantes, professores, funcionários e pessoas provenientes da microrregião que vieram em busca de oportunidades oferecidas pela instituição. Diante dessa transformação, a cidade de Viçosa cresceu em resposta às demandas geradas pela UFV. É possível afirmar que essa ampliação interferiu espontaneamente na vida da população que passou a viver, praticamente, em função da universidade.

Pretende-se discutir neste artigo as transformações provocadas pela federalização da UFV no espaço urbano de Viçosa. O relevo de "Mares de Morros" comprime a cidade entre morros e vales, a topografia é menos acidentada na área ocupada pela universidade. Hoje, a região central da cidade encontra-se adensada e verticalizada, resultado da federalização e da demanda gerada pela ampliação de vagas e criação de novos cursos ${ }^{4}$ da UFV, proporcionadas pela Reestruturação e Expansão das Universidades Federais (REUNI) ${ }^{5}$. O projeto, que tem como objetivos ampliar as condições de acesso e permanência na educação superior, foi implantado na UFV a partir de 2000, desde então, proprietários fundiários e imobiliários passaram a dominar

${ }^{4}$ Engenharias Mecânica e Química (2007), licenciaturas noturnas em Matemática, Física, Química, Ciências Biológicas e Ciências Sociais (2009), Enfermagem (2009) e Medicina (2010)

${ }^{5}$ Programa de Apoio a Planos de Reestruturação e Expansão das Universidades Federais, criado pelo Decreto nº 6.096 , de 24 de abril de 2007. 
ainda mais o cenário econômico do município, especulando sobre a terra existente e investindo em terrenos que atendam a demanda futura. Nesse período, proliferou a construção de novos edifícios no centro e a demolição de antigas construções. Nota-se nas áreas periféricas o surgimento de novos parcelamentos de solo, como é o caso dos localizados nas comunidades Violeira, Paraíso, Cristais, Canela e Romão dos Reis.

Destarte, este artigo tem como objetivo analisar a expansão da cidade de Viçosa sob a luz da federalização da UFV. No que diz respeito à metodologia, o artigo foi elaborado por meio de pesquisa bibliográfica, a partir de leituras que oferecessem embasamento teórico acerca do histórico de urbanização e desenvolvimento do município. O levantamento das informações contou com interpretação de dados censitários e foram usados artigos de jornais locais, para acompanhar a evolução da cidade.

\section{Revisão de literatura}

O rápido crescimento urbano é uma característica dominante do desenvolvimento das economias mais avançadas. Como expressa David Clark (1991):

A expansão das grandes cidades e de suas crescentes áreas de influência iniciou uma mudança que passou de lugares e padrões de vida dominantemente rurais para predominantemente urbanos, afetando a maioria dos países nos últimos anos. Atualmente, não somente grandes números de pessoas vivem em cidades ou em suas adjacências imediatas, mas segmentos inteiros da população são completamente dominados pelos valores, expectativas e estilos de vida urbanos. (p. 61)

Monte-Mór (2006) demonstra que cada vez mais as fronteiras entre o espaço urbano e o rural são difusas e de dificil identificação. É possível supor que hoje tanto a cidade como o campo não são mais conceitos puros, de fácil identificação ou delimitação. Cidade e campo constituem a centralidade e a periferia do poder na organização social.

As cidades garantem a diversidade e a escala da vida social, bem como a competição e a cooperação, características da vida humana contemporânea. Os campos, por sua vez, tão diversos entre si, garantem, também, diversidades dentro da sua homogeneidade extensiva de suas escalas de produção, quanto tomados de forma abrangente. (MONTE-MÓR, 2006, p. 11) 
Milton Santos (2009), na obra A urbanização brasileira, comenta sobre a transformação do conteúdo das cidades. Segundo o autor, antes "as cidades dos notáveis: do padre, do tabelião, do telegrafista; hoje cede lugar às cidades econômicas: do agrônomo, veterinário, bancário”. Monte-Mór (2006) completa que:

(...) o campo, até então predominantemente isolado e autossuficiente, passou a depender da cidade para sua própria produção, das ferramentas e implementos aos bens de consumo de vários tipos. Para Lefebvre (1999) essa inflexão significa a subordinação total do campo à cidade. (p.13)

A urbanização brasileira, segundo Maricato (2000), ocorreu no período desenvolvimentista sob a égide da industrialização e foi caracterizada pela industrialização com baixos salários, mercado residencial restrito, custo de reprodução da força de trabalho que não incluía o custo da moradia, proporcionando o aumento das favelas, dos lotes clandestinos, das autoconstruções e da exclusão do acesso à moradia.

Como enuncia Maricato (2000), na década de 1940 apenas $31 \%$ da população brasileira era urbana, "as cidades eram vistas como o lado moderno e avançado de um país predominantemente agrário e atrasado". No início do século XXI a imagem de cidade é bem distinta. Hoje elas expressam a reprodução do modo de vida desigual, são lugares de especulação financeira e imobiliária, apresentam condições precárias de moradia, pobreza, desemprego, violência.

A origem da cidade industrial no Brasil ocorreu a partir de duas vertentes básicas, de acordo com Monte-Mór (2006):

(...) a primeira, a transformação da cidade política em cidade mercantil, marcada pela presença do capital exportador e da concentração de comércio e serviços centrais de apoio às atividades produtivas rurais em centro de produção industrial; a segunda, a criação e captura de pequenas cidades como espaços de produção monoindustrial por grandes indústrias. Apenas essas cidades industriais congregavam as condições estabelecidas pelo capitalismo industrial, em que o Estado proporcionava as condições gerais de produção para a indústria, por meio da regulação das relações entre capital e trabalho e investimentos em infraestrutura. (p. 15)

Esse mesmo autor utiliza o termo urbanização extensiva para caracterizar a materialização sociotemporal dos processos de produção e reprodução resultantes do confronto do industrial com o urbano, acrescido das dimensões sociopolítica e cultural intrínsecas à polis: 
(...) é essa espacialidade social resultante do encontro explosivo da indústria com a cidade - o urbano - que se estende com as relações de produção (e sua reprodução) por todo o espaço onde as condições gerais de produção (e consumo) determinadas pelo capitalismo industrial de Estado impõem-se à sociedade burocrática de consumo dirigido carregando, no seu bojo, a reação e a organização política próprias da cidade. Essa é a realidade - a sociedade urbana - que se impõe hoje como virtualidade e objetividade no Brasil, constituindose em condição para a compreensão do espaço social contemporâneo. (MONTE-MÓR, 2006, p. 15)

Milton Santos (2009) chama atenção para a ocupação de vastas superfícies das cidades, entremeadas de vazios. Para ele as cidades são grandes porque há especulação e vice-versa. Esse discurso se encaixa perfeitamente no caso de Viçosa. Segundo o autor:

A especulação imobiliária deriva da conjugação de dois movimentos convergentes: a superposição de um sítio social ao sítio natural, e a disputa entre atividades ou pessoas por dada localização. A especulação se alimenta desta dinâmica, que inclui expectativas. Criam-se sítios sociais, uma vez que o funcionamento da sociedade urbana transforma seletivamente os lugares, afeiçoando-os às suas exigências funcionais. É assim que certos pontos se tornam mais acessíveis, certas artérias mais atrativas e, também, uns e outras, mais valorizados. (SANTOS, 2009, p. 106)

\section{Metodologia}

No que tange à metodologia, o artigo consistiu em uma abordagem qualitativa da evolução urbana de Viçosa, Minas Gerais, a partir da federalização do principal agente produtor de seu espaço urbano, a UFV.

O artigo foi elaborado por meio de pesquisa bibliográfica, a partir de leituras que oferecessem embasamento teórico acerca do histórico de urbanização e desenvolvimento do município. O levantamento das informações contou com interpretação de dados censitários e foram usados artigos de jornais locais, para acompanhar a evolução da cidade. Além do histórico de urbanização, optamos por descrever os principais parcelamentos de solo realizados nas áreas periurbanas da cidade nos últimos anos. 


\subsection{Caracterização da área de estudo}

O município de Viçosa pertence à mesorregião da Zona da Mata e à microrregião de Viçosa, localizadas no estado de Minas Gerais. Com área estimada de $300,15 \mathrm{~km}^{2}$ e altitude no ponto central da cidade de 649 metros, é limitado pelos municípios de Teixeiras e Guaraciaba ao norte; Paula Cândido e Coimbra ao sul; Cajuri e São Miguel do Anta a leste e Porto Firme a oeste.

Figura 1 - Microrregião de Viçosa (MG) e seus municípios do entorno

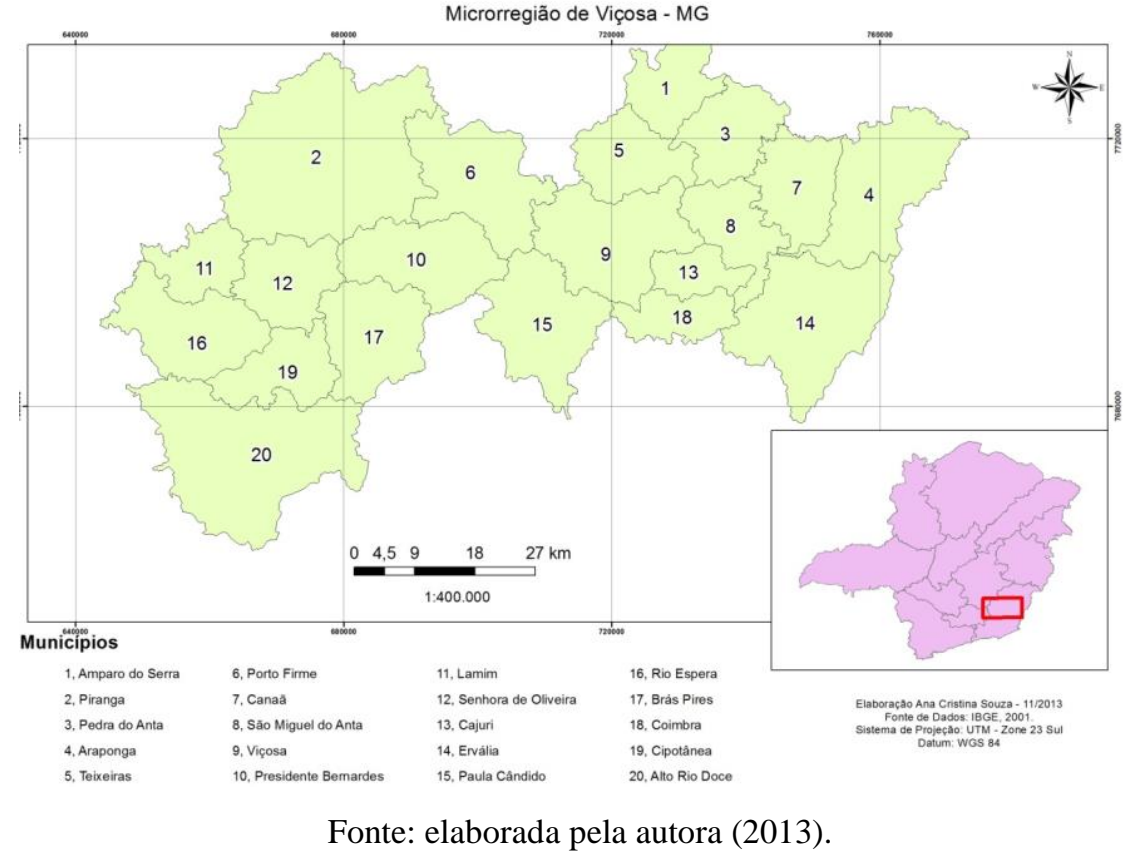

A cidade faz parte da Bacia Hidrográfica do rio Doce, e apresenta como principais cursos d'água o rio Turvo Sujo e seu subafluente, o ribeirão São Bartolomeu, principal curso d'água que atravessa a área urbana e se constitui em uma das principais fontes de água para a população da cidade, como também é um dos principais depositários de seus esgotos. Próximo às margens desse ribeirão, teve início o primeiro núcleo urbano que originou a cidade e, ao longo de suas margens, Viçosa se expandiu (RIBEIRO FILHO, 1997).

Segundo o IBGE, a cidade encontra-se situada no Planalto de Viçosa, no Domínio Morfoclimático dos Mares de Morros, entre a Serra da Mantiqueira, Serra do Caparaó e Serra da Piedade. Nessa região predominam rochas gnáissicas précambrianas. 
O município está em uma região onde a topografia é fortemente acidentada, apresentando porções reduzidas de área plana $\mathrm{O}$ relevo é classificado em sua maior parte como acidentado, com $85 \%$ montanhoso, $12 \%$ ondulado e $3 \%$ plano. Devido ao crescimento demográfico, Viçosa teve a necessidade de se expandir e enfrenta problemas com relação ao uso e à ocupação do solo. Os responsáveis pela ocupação da cidade não tiveram os devidos cuidados, e, pressionados pela elevação da terra, ocuparam áreas onde a topografia ultrapassa os $30 \%$ de declividade, encostas e topos de morros (STEPHAN, 1997).

Viçosa conta com quatro distritos: a sede ${ }^{6}$, Silvestre, São José do Triunfo e Cachoeira de Santa Cruz. A cidade possui em sua área um fixo de importância nacional, a UFV, e conta com uma população urbana estimada em 92,4\%. Em seu trabalho, Mello (2002), baseado no IBGE, destaca temporalmente o processo de crescimento da cidade de Viçosa:

Segundo dados levantados pelo IBGE, até o ano de 1960 a população de Viçosa era de 20.846 habitantes. Desse total, 9.221 habitantes residiam em área urbana e os 11.625 restantes encontravam-se espalhados na zona rural. Na década de 60, houve uma inversão nesse quadro, residindo na sede do município, 15.551 habitantes e na zona rural 10.226, perfazendo um total de 25.777 habitantes. Nas décadas seguintes houve grande crescimento populacional, aumentando a discrepância entre os números relacionados com a população urbana e rural. No censo demográfico de 2000, Viçosa aparece com 59.792 habitantes residindo na sede do município e 5.062 na zona rural e demais distritos pertencentes ao município. (p. 38)

O instituto Census $^{7}$ (2014) destaca a passagem da população antes predominantemente rural para urbana. A população viçosense triplicou nos últimos 44 anos, passando de 25.784 habitantes em 1970 para 77.502 em 2014. Esse crescimento populacional foi acompanhado de um significativo processo de urbanização, que, em Viçosa, fez com que a população urbana passasse de 65,9\% do total em 1970, para 93,2\% em 2010, e resultou na redução da participação da população rural de 34,07 \% em 1970, para 6,80\% em 2014.

Os dados da Tabela 1 mostram que, desde a década de 1970, existe um aumento significativo da população urbana de Viçosa ao mesmo tempo que evidenciam o declínio do número de habitantes da área rural. A partir da referida década, a cidade

\footnotetext{
${ }^{6} \mathrm{Na}$ sede, que cresceu junto ao estreito vale do ribeirão São Bartolomeu e em seguida ocupou as encostas, ainda encontram-se alguns casarões e sobrados históricos que datam dos séculos XIX e XX, em meio à densa verticalização da área central.

${ }^{7}$ Centro de Promoção do Desenvolvimento Sustentável, fundado em 2000. Organização Não Governamental dedicada a estudos, formação e assessoria nas áreas social, urbanística, ambiental e de gestão pública.
} 
apresentou um elevado aumento de sua população urbana, impulsionado pelo fluxo migratório de populações atraídas pela UFV. Dessa forma, a federalização da UFV levou a uma expansão de loteamentos, edifícios e condomínios fechados. Contudo, também provocou a migração de uma população de classe baixa atraída pela oportunidade de emprego e, consequentemente, pelas melhores condições de vida, ocupando as áreas periféricas.

Tabela 1 - Evolução da população urbana e rural - Período 1970 a 2014 - Viçosa (MG)

\begin{tabular}{|c|c|c|c|c|c|c|}
\hline \multirow[t]{3}{*}{ ANOS } & \multicolumn{6}{|c|}{ POPULAÇÃO } \\
\hline & \multicolumn{2}{|c|}{ URBANA } & \multicolumn{2}{|c|}{ RURAL } & \multicolumn{2}{|c|}{ TOTAL } \\
\hline & ABSOLUTA & $\%$ & ABSOLUTA & $\%$ & ABSOLUTA & $\%$ \\
\hline 1970 & 17.000 & 65,93 & 8.784 & 34,07 & 25.784 & 100,00 \\
\hline 1980 & 31.179 & 80,60 & 7.507 & 19,40 & 38.686 & 100,00 \\
\hline 1991 & 46.456 & 89,93 & 5.202 & 10,07 & 51.658 & 100,00 \\
\hline 2000 & 59.792 & 92,19 & 5.062 & 7,81 & 64.854 & 100,00 \\
\hline 2010 & 67.305 & 93,19 & 4.915 & 6,81 & 72.220 & 100,00 \\
\hline 2014 & 72.231 & 93,20 & 5.271 & 6,80 & 77.502 & 100,00 \\
\hline
\end{tabular}

O censo de 2010 apontou que 72.220 pessoas residiam no município. Segundo dados divulgados pelo IBGE, em agosto de 2013, Viçosa possuía população estimada em 76.747 pessoas. A diferença representou um acréscimo de 5,8\% com 4.527 novos moradores. Esse número não inclui a população flutuante do município, formada basicamente por estudantes universitários $\left(\mathrm{UFV}^{8}, \mathrm{FDV}^{9}\right.$, Univiçosa ${ }^{10}$ / ESUV ${ }^{11}$, UNOPAR) com número estimado em aproximadamente 20 mil pessoas. Esses são moradores dos alojamentos das universidades, mensalistas em hotéis, inquilinos em domicílios familiares e moradores nas chamadas repúblicas estudantis (CENSUS, 2014). A cidade é a quinta mais populosa da Zona da Mata, atrás apenas de Juiz de Fora, Ubá, Muriaé e Manhuaçu.

O município vive em função da universidade. A economia local, baseada no setor de serviços, é dependente da população flutuante. O instituto Census (2014) enfatiza que são vários os empreendimentos na área de prestação de serviços criados para atender a demanda proveniente dos estudantes, servidores e professores da UFV, com destaque para a indústria da construção civil, cujo crescimento impulsionado pela expansão da universidade produz impacto em todos os setores da economia, sobretudo

\footnotetext{
${ }^{8}$ Criada pelo Decreto n ${ }^{\circ} 6.053$, de 30 de março de 1922, e inaugurada em 1926.

${ }^{9}$ Fundada em 1999, possuía em 2014 sete cursos de graduação e dois de pós-graduação.

${ }^{10}$ Fundada em 2005, possuía em 201416 cursos de graduação e 12 de pós-graduação.

${ }^{11}$ Criada em 2001, a escola incorporou-se à UNIVIÇOSA em 2012.
} 
no comércio local de materiais de construção, serralherias, carpintarias, de serviços de corretagem e locação de imóveis.

\section{Fundamentos históricos}

Para compreender a atual configuração espacial da cidade, é necessário entender os fundamentos históricos de formação do município. Ainda que os primeiros habitantes da região tenham sido os índios puris e aimorés, Ribeiro Filho (1997) ilustrou que o primeiro adensamento do espaço urbano de Viçosa encontrou-se vinculado à queda da extração de ouro em Minas Gerais. A população migrante de Ouro Preto, Mariana e Piranga se instalou nessa região entre o final do século XVIII e início do século XIX e dedicou-se à procura de terras férteis para a produção agrícola.

$\mathrm{O}$ arraial teve origem em área de vale, próximo às margens do afluente do rio Turvo Sujo, o ribeirão São Bartolomeu. Como diversos municípios brasileiros, Viçosa surgiu através da doação de terras para a Igreja. As primeiras construções e um pequeno povoado surgiram próximos de uma capela erguida em homenagem a Santa Rita de Cássia, onde hoje se situa a atual rua dos Passos.

O primeiro traçado urbano de Viçosa se deu nos primórdios do século XIX, quando, pela autorização da Igreja, o padre local Francisco José da Silva iniciou a construção de uma nova capela em homenagem a Santa Rita. Assentada em um terreno mais plano em relação à primeira, a capela foi erguida próximo a onde hoje se encontra a atual matriz. A escolha dessa nova área impulsionou a ocupação do entorno e transformou-se na localização mais importante e populosa do arraial.

Em 1819 com a morte do Pároco Manoel Inácio de Castro, latifundiário local, parte de suas terras foi dividida e colocada à venda. Esse primeiro "loteamento" atraiu pessoas principalmente de Piranga (RIBEIRO FILHO, 1997, p. 97).

O distrito de Santa Rita do Turvo foi criado em 1832, pelo então presidente do Conselho da Regência Trina do Império, padre Diogo Antônio Feijó; já o município surgiu em 1871. Na oportunidade da elevação da vila à categoria de cidade, em 1876, trocou-se o topônimo para o de Viçosa de Santa Rita, em homenagem ao Bispo D. Viçoso, da Arquidiocese de Mariana. 
Em 1884 a chegada da estrada de ferro "The Leopoldina Railway" trouxe a Viçosa um sentido mercantil e de prestação de serviços. A presença da ferrovia foi decorrente da necessidade de transporte da produção regional, principalmente de café. "No centro da cidade, foi construída a estação ferroviária, onde hoje funciona o Espaço Cultural Hervê Cordovil. Esse ramal da ferrovia foi fundamental para o desenvolvimento da cidade" (ONG CENSUS, 2014). A abertura da ferrovia possibilitou a incorporação e ocupação de novas áreas ao longo do seu trajeto e foi considerada um fator de direcionamento do crescimento, o segundo marco mais importante na formação do espaço construído da cidade (RIBEIRO FILHO, 1997). O instituto Census (2014) também menciona a importância da ferrovia para o desenvolvimento da cidade:

A cultura cafeeira provocou novo impulso à economia local, sobretudo a partir da chegada da ferrovia. O crescimento econômico deu força política à região que, desde o império, teve seus representantes no parlamento federal e, no início do século XX, levou Arthur Bernardes ao Palácio da Liberdade e, mais tarde, ao cargo de presidente da República. (CENSUS, 2014)

Em um primeiro momento, a urbanização de Viçosa foi impulsionada pelo potencial da atividade agrícola que se tornou fator de atração para a população de outras cidades, junto com alguns fatores de repulsão dessas cidades, como a queda da extração do ouro. As Figuras 2a e 2b demonstram a organização do espaço urbano de Viçosa nos primórdios do século XX.

Figuras $2 \mathrm{a}$ e $2 \mathrm{~b}$ - Vista geral de Viçosa em 1898
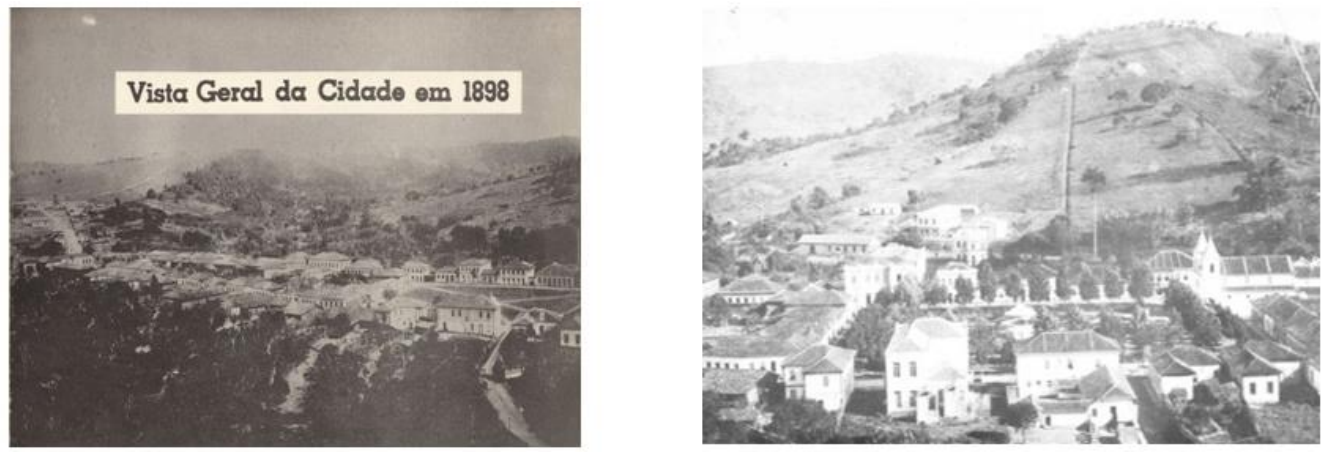

Fonte: A história de Viçosa. <http://redlinemg.com/vicosa-mg/>; Vista parcial da Praça da Matriz, 1916. http://www.dpi.ufv.br/

Segundo Ribeiro Filho (1997), na primeira década do século XX o espaço urbano de Viçosa se encontrava em considerável expansão e já havia modificações na sua forma urbana, referenciadas no urbanismo modernista e sanitarista. Foram 
realizadas obras como a construção da avenida Santa Rita, desenhada nos moldes dos bulevares franceses, ligando a rua do Cruzeiro (atual rua Padre Serafim) à estrada que levava à fazenda Conceição.

A partir da década de 1920 o espaço urbano da cidade transformou-se completamente com a implantação de duas importantes obras que vieram a impulsionar uma considerável expansão urbana. A Escola Superior de Agricultura e Veterinária (ESAV) inaugurada em 1926 e o Patronato Agrícola Arthur Bernardes. Stephan (2011) destaca que ambas as obras idealizadas por influência do viçosense Arthur da Silva Bernardes, então presidente da Província de Minas Gerais, foram vistas como uma maneira de fortalecer o Estado diante de São Paulo, no que tange aos aspectos políticos e econômicos.

De acordo com instituto Census (2014), “o Patronato Agrícola Arthur Bernardes, edificado no período de 1926 a 1927, no imóvel denominado Fazenda da Vargem, era um estabelecimento de ensino dirigido ao atendimento de menores infratores".

A construção da ESAV foi o elemento primordial de incentivo ao processo de urbanização acelerado do município, que passou a experimentar uma nova fase em seu processo de urbanização e rapidamente se tornou destaque na região e no estado de Minas Gerais. A escola foi construída a aproximadamente $1 \mathrm{~km}$ do centro da cidade, em uma área de topografia privilegiada, constituindo uma barreira à expansão. A ESAV não só se transformou em um grande centro de educação, como também influenciou, ao ocupar as áreas mais planas, as futuras obras da cidade. Dessa maneira, os moradores foram levados a construírem suas casas em terrenos mais acidentados, como os próximos ao São Bartolomeu.

Nos anos seguintes à inauguração da escola, a cidade atravessou por transformações estruturais urbanas impulsionadas pela vinda de novos moradores atraídos pela oportunidade de emprego na cidade e região, inaugurando uma nova função urbana para a cidade.

Tendo em vista o desenvolvimento da escola, o governo do Estado a transformou em Universidade Rural do Estado de Minas Gerais (UREMG) em 1948, composta pela ESAV, pela Escola Superior de Ciências Domésticas, pela Escola de Especialização, pelo Serviço de Extensão e Serviço de Experimentação e Pesquisa. Com 
a expansão de seus cursos e estruturas, a população urbana da cidade aumentou significativamente. Devido a sua consistente base, a UREMG adquiriu renome em todo o país, o que motivou o governo a federalizá-la em 1969. A antiga UREMG passou a denominar-se Universidade Federal de Viçosa.

\section{A evolução urbana viçosense após 1970}

Com a federalização da UFV o processo de urbanização desordenado ampliou-se intensamente. O aporte de recursos para manutenção, criação de novos cursos, ampliação física e aumento do número de funcionários foi proporcionado pelo governo federal somente à universidade, ao passo que a cidade não recebia recursos suficientes para cobrir os problemas referentes a essa expansão. Esse aumento na demanda de novos investimentos foi o fator decisivo para a urbanização desordenada. O poder público municipal não estava preparado para receber tão rápido contingente de pessoas e administrar essa nova demanda que surgia em função da universidade (RIBEIRO FILHO, 1997).

Stephan e Ribeiro Filho (2001), apontam que com a expansão das atividades a partir da criação de novos cursos na UFV, a cidade atraiu um número significativo de pessoas, novos estudantes, professores, funcionários, que, somados ao contingente de mão de obra em busca de oportunidades de trabalho em obras na cidade e na própria universidade, influenciaram na constituição de um espaço urbano desordenado e cada vez mais desigual. Parte dessa população, inserida precariamente no mercado de trabalho local, buscou como moradia soluções informais na periferia da cidade, onde elevaram suas casas à revelia das leis existentes, em sistemas de autoconstrução.

Surgiram diversos novos bairros em decorrência da federalização da universidade, como Bela Vista, Fátima, Belvedere. Ribeiro Filho (1997) chama atenção para o processo de verticalização do bairro Ramos, na sua parte baixa, próxima ao centro, e no início do Clélia Bernardes, ao longo de sua avenida principal. A localização próxima à universidade fez com que rapidamente eclodissem residências multifamiliares para atender as demandas geradas por habitação.

Para Ribeiro Filho (1997, p. 144): 
O expressivo contingente populacional que migrou para Viçosa, a partir da década de 70 , pressionou a expansão do espaço urbano não só horizontalmente, com a incorporação de novos loteamentos, mas também verticalmente, com a construção de novas edificações. Neste sentido, a área central da cidade foi a primeira a ser verticalizada, por ser a mais bem provida de infraestruturas, equipamentos e serviços urbanos e a mais valorizada. Esta verticalização aconteceu com a perda de alguns casarões [...] e com eles, parte de sua história. Este processo de verticalização se iniciou na Rua Arthur Bernardes e na Travessa Sagrados Corações.

Nas décadas de 1980 e 1990 confirmou-se uma tendência que começou a se esboçar na década de 1970, intensificou-se o processo de adensamento do centro e dos bairros próximos a ele. Surgiram os primeiros condôminos horizontais, como o Condomínio Residencial Bosque do Acamari de 1983. Esse acentuado crescimento resultou em uma série de problemas típicos de metrópoles brasileiras: deficiência de infraestrutura, favelas e vasto processo de verticalização nas áreas centrais. O processo de urbanização gerou um crescimento econômico significativo, mas acompanhado das desigualdades sociais, da exclusão e segregação. "Neste período o espaço urbano de Viçosa foi ocupado sem qualquer controle do poder público" (RIBEIRO FILHO, 1997).

Segundo Portugal (2009), a emergência de condomínios fechados, evidenciando uma tendência à segregação no espaço urbano, chama a atenção em Viçosa por ser uma realidade típica das grandes metrópoles. A autora aponta que, em 2009, a cidade possuía sete condomínios residenciais fechados: Parque do Ipê, Bosque do Acamari, Recanto da Serra, Jardins do Vale, Monte Verde, Caminho dos Lagos e Condomínio Bretas.
Além desses condomínios a cidade de Viçosa possui duas situações muito particulares quanto ao tipo de moradia em condomínios residenciais. Os casos do bairro Inconfidentes, Júlia Mollá, caracterizam-se como tentativas de se formar um condomínio fechado, porém, esses espaços não são fechados, ou seja, não possuem portaria que controla a entrada e saída de pessoas e não tem muro de divisas. Todavia são bairros de classe média alta. (PORTUGAL, 2009, p. 12)

Segundo dados do Serviço Autônomo de Água e Esgoto (SAAE) atualmente existem 11 condomínios fechados na cidade: Acamari, Monte Verde, Otávio Pacheco, Jardins do Vale, Caminho dos Lagos, Parque do Ipê, Recanto da Serra, Vereda do Bosque, Canto dos Sonhos, Vale das Acácias e Vale Verde. 


\section{Parcelamentos atuais}

Buscamos aqui apresentar alguns dos parcelamentos de terra construídos nas áreas periféricas da cidade, possivelmente voltados para especulação imobiliária, caso essas áreas se tornem urbanas no futuro. No primeiro caso, há o parcelamento localizado próximo ao bairro Romão dos Reis, conhecido como "Novo Romão dos Reis". É provável que esses parcelamentos tenham sido realizados sem Estudos de Impacto Ambiental e sem fiscalização por parte do poder público.

Figuras 4a e 4b - Parcelamento de solo na localidade "Novo Romão dos Reis
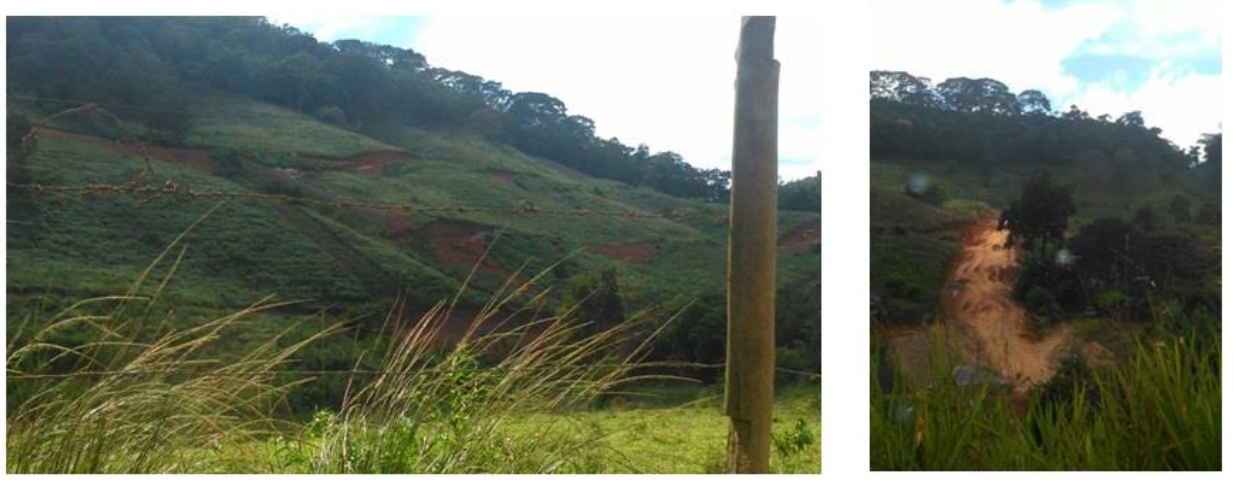

Fonte: arquivo pessoal (2014).

O segundo caso localiza-se em uma área rural conhecida como "Canela". O terreno está localizado em um vale. Nas imagens a seguir é possível notar o aterramento de um curso d'água para construção de lotes e até mesmo sua comercialização. É válido mencionar que o parcelamento de solo rural deve ser submetido ao INCRA, que é o órgão competente. 
Figuras 5a e 5b - Parcelamento de solo em área rural, em "Canela"
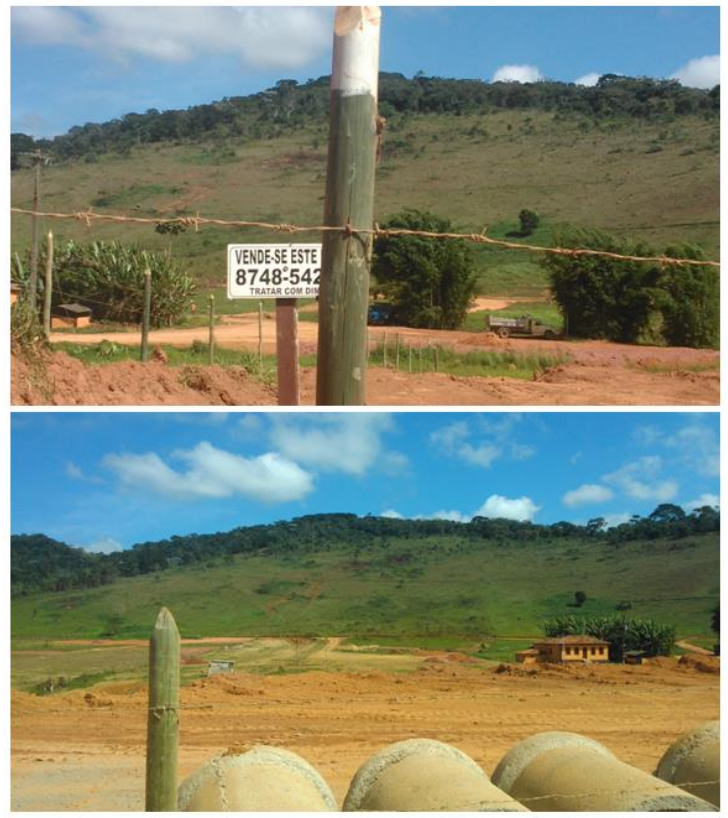

Fonte: arquivo pessoal (2014).

O terceiro caso corresponde a uma região pouco habitada denominada Cristais, recentemente transformada em urbana pela legislação 2272/2012. A área é vizinha ao campus da UFV, portanto muito valorizada. Essa nova área urbana foi criada sem consulta à população residente nas proximidades. O novo perímetro urbano não incluiu o único conjunto de casas existentes no local. Para a área foram desenvolvidos projetos que incluem shopping centers, conjuntos de edificações multifamiliares, escola e dois condomínios fechados.

Figura 6 - Entrada do Condomínio Vale Verde, construído na localidade "Cristais"

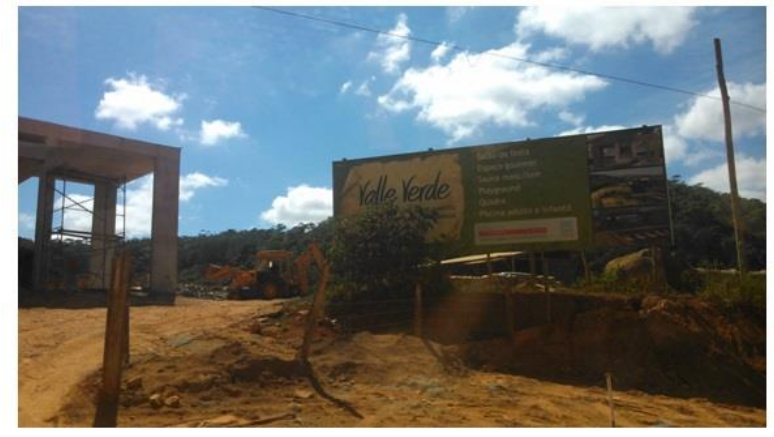

Fonte: arquivo pessoal (2014).

Encontra-se em trâmite no legislativo municipal desde 2012 outro projeto de transformação de área rural em área urbana. O projeto de Lei n ${ }^{\circ}$ 50/2012 dispõe sobre a criação da Zona Residencial 5 - ZR5, que abrangerá a região da comunidade "Paraíso". 
Devido à pressão popular, ele ainda não foi aprovado. $O$ projeto foi colocado em pauta em reuniões e audiências públicas e unanimemente rejeitado pela população Viçosense, moradores da comunidade Paraíso, diretoria do Instituto de Planejamento Municipal (IPLAM), membros do Conselho de Planejamento Municipal (COMPLAN) e representantes de organizações civis. Com exceção dos representantes do poder público municipal, diretoria do Serviço Autônomo de Água e Esgoto (SAAE) e incorporadores/promotores imobiliários.

O Plano Diretor vigente em Viçosa, de 2000, mostra que o local não deve sofrer adensamento populacional por ser uma região frágil, que abriga as nascentes do principal curso d'água que abastece o município. Há anos é reivindicada a criação de uma Área de Proteção Ambiental (APA) do São Bartolomeu. A proposta da criação da ZR-5 almejou estabelecer regras para uma área ainda com características rurais, que aos poucos estava adquirindo usos urbanos em algumas de suas partes.

\section{Considerações finais}

Conforme pode ser observado, Viçosa (MG) apresentou um crescimento acentuado proporcionado pela existência da Universidade Federal de Viçosa. No início do século XX, com a implantação da ESAV, houve investimentos em infraestrutura voltados para atender à demanda da "cidade universitária", que então surgia.

Com a federalização da UFV, Viçosa experimentou um crescimento vertical e horizontal a partir dos anos 1970. Após essa década esses investimentos, sobretudo em habitação, tornam-se mais intensos uma vez que a principal atividade econômica do município se volta para a universidade.

Em seguida, nos anos 2000, essa expansão acentuou-se, proporcionada principalmente pela criação de novos cursos da Universidade Federal de Viçosa, empreendidos através da política expansionista do REUNI. A atuação do mercado imobiliário em Viçosa tem sido gerada principalmente pela crescente demanda em função da expansão da UFV e da instalação de instituições privadas de ensino superior.

A respeito do direcionamento do crescimento da cidade, nota-se que começa a haver expansão sobre áreas periféricas e rurais. A cidade se expande horizontalmente e os vazios urbanos são deixados para trás. 


\section{REFERÊNCIAS}

CLARK, D. Introdução à geografia urbana. 2. ed. Rio de Janeiro: Bertrand Brasil, 1991.

CRUZ, T. A. (Coord.). Retrato social de Viçosa V. Viçosa, MG: Census, 2014. 91p.

MARICATO, E. As ideias fora do lugar e o lugar fora das ideias: Planejamento urbano no Brasil. In: ARANTES, Otília; VAINER, Carlos; MARICATO, Ermínia. A cidade do pensamento único: desmanchando consensos. Petrópolis, RJ: Vozes, 2000. p. 121192.

MELLO, F. A. O. Análise do processo de formação da paisagem urbana de Viçosa, Minas Gerais. 2002. 92f. Dissertação (Mestrado em Ciências Florestais) Departamento de Engenharia Florestal, Universidade Federal de Viçosa, Viçosa, 2002.

MONTE-MÓR, R. L. O que é o urbano, no mundo contemporâneo. Revista Paranaense de Desenvolvimento, Curitiba, n. 111, p. 9-18, jul./dez. 2006.

MONTE-MÓR, R. L. Outras fronteiras: novas espacialidades na urbanização brasileira. In: Urbanização brasileira: redescobertas. Belo Horizonte: Editora Arte, 2003. p. 260-271.

PORTUGAL, J. G. A sociabilidade em condomínios fechados: o caso do condomínio residencial Recanto da Serra em Viçosa-MG. 2009. Dissertação (Mestrado em Economia Doméstica) - Universidade Federal de Viçosa, Viçosa, 2009.

RIBEIRO FILHO, G. B. A formação do espaço construído: Cidade e legislação urbanística em Viçosa, MG. 1997. 244 f. Dissertação (Mestrado em Urbanismo) Faculdade de Arquitetura e Urbanismo - Universidade Federal do Rio de Janeiro, Rio de Janeiro, 1997.

SANTOS, M. A urbanização brasileira. 5. ed., 2. reimpr. São Paulo: EDUSP, 2009.

STEPHAN, I. I. C.; RIBEIRO FILHO, G. B. Avanços e limites na implantação de um sistema de planejamento em Viçosa - MG. In: Anais V Congresso de Ciências Humanas, Letras e Artes. 28 a 31 de agosto de 2001, UFOP: Ouro Preto, 2001. 
STEPHAN, I. I. C. Campus da UFV oito décadas de arquitetura. Arquitextos. Ano 11. Maio 2011.

STEPHAN, I. I. C. Rua Milton Bandeira: uma síntese de problemas urbanos. Folha da Mata, Viçosa-MG, v. 34, n. 1470, 26 abr. 1997.

Recebimento dos originais: $20 / 03 / 2014$

Aceitação para publicação: 15/06/2014 